\title{
EL DERECHO SEÑORIAL EN LA CONSTITUCIÓN DE 1812: UN PROBLEMA DE INTERPRETACIÓN JURÍDICA
}

\author{
José Manuel Cardona Amaya ${ }^{1}$
}

\section{DOI: https://doi.org/10.5377/Ird.v41i1.10499}

\section{RESUMEN}

En este artículo se estudia la crisis gestada en la Alcaldía Mayor de Tegucigalpa por la interpretación que varios pueblos indígenas dieron a ciertos artículos de la Constitución Política de la Monarquía Española, durante su segundo periodo de vigencia a partir de 1820. Esta Carta Magna introdujo una serie de innovaciones liberales, entre ellas la abolición de las distinciones de casta (indios, negros, mulatos) y estados (eclesiástico, noble, común). Con base en esto, varios pueblos indígenas alegaron que la Constitución les eximía de pagar el tributo señorial que se les había impuesto en 1523, contrariando así a las autoridades locales del Imperio Español, a quienes les correspondía cobrar el derecho en nombre del Rey. Este conflicto de interpretación constitucional en materia tributaria fue el primero de su clase en la vida constitucional de Honduras, por lo que su estudio permite una aproximación a la conformación de las instituciones democráticas en el país. La investigación se ha realizado utilizando documentación de la época contenida en el Fondo Colonial del Archivo Nacional de Honduras, utilizándose una metodología comparativa para analizar los textos.

\section{PALABRAS CLAVE:}

Constitución, Interpretación, Pueblos Indígenas, Monarquía

Fecha de recepción: 18 de febrero de 2020 Fecha de aprobación: 18 de noviembre de 2020

1 Docente del Departamento de Historia de la Facultad de Ciencias Sociales de la Universidad Nacional Autónoma de Honduras. Master en Historia Social y Cultural. Licenciado en Historia. Correo Electrónico: jmcardona@unah.edu.hn 


\title{
THE LORDLY RIGHT IN THE CONSTITUTION OF 1812: A PROBLEM OF LEGAL INTERPRETATION
}

\section{José Manuel Cardona Amaya²}

\section{DOI: https://doi.org/10.5377//rd.v41i1.10499}

\begin{abstract}
:
This article studies the crisis developed in the Mayoralty of Tegucigalpa caused by the interpretation that several indigenous peoples gave to certain articles of the Political Constitution of the Spanish Monarchy, during its second period of validity from 1820. This Magna Carta introduced a series of liberal innovations, among them the abolition of caste distinctions (Indians, blacks, mulattos) and states (ecclesiastical, noble, common). Based on this, several indigenous peoples claimed that the Constitution exempted them from paying the stately tribute that had been imposed on them in 1523, thus contradicting the local authorities of the Spanish Empire, who were entitled to charge the right in the name of the King. This conflict of constitutional interpretation in tax matters was the first of its kind in the constitutional life of Honduras, so that its study allows an approximation to the conformation of democratic institutions in the country. The research has been carried out using documentation of the time contained in the Colonial Fund of the National Archive of Honduras, using a comparative methodology to analyze the texts.
\end{abstract}

\section{KEYWORDS:}

Constitution, Interpretation, Indigenous Peoples, Monarchy

Date received: February 18, 2020 Approval date: November 18, 2020

2 Professor of the Department of History of the Facultad de Ciencias Sociales de la Universidad Nacional Autónoma de Honduras. . Master in Social and Cultural History. Degree in History. Email: jmcardona@,unah.edu.hn 


\section{INTRODUCCIÓN}

La vida constitucional de Honduras inició con la promulgación de la Constitución de la Monarquía Española de 1812 (Saenz, 2015), representando este documento el fin del absolutismo monárquico que había reinado desde inicios del periodo colonial y la implementación de un nuevo pacto entre la corona castellana y sus provincias. La puesta en vigencia de la Constitución significó el fin de un sistema de derecho enraizado en el feudalismo y el inicio de una administración moderna, transformándose los antiguos vasallos del Rey de España en pares ciudadanos sin importar su condición de nacimiento y, pasando las cortes de la nobleza a ser instituciones democráticas. El cambio paradigmático generado por la Constitución de 1812 fue tal, que su estudio sigue siendo un campo fructuoso en la ciencia, como lo demuestran las múltiples publicaciones en honor a su bicentenario, entre las que se enumeran trabajos de la Agencia Española de Cooperación Internacional para el Desarrollo (2012), Georges Lomné (2012), Juan Cassagne (2012) y Nilda Garay (2012).

La transición de un régimen absolutista a una monarquía constitucional generó una serie de conflictos en el Imperio Español. En este artículo se estudia un problema específico relacionado con la interpretación constitucional, a saber: que varios pueblos indígenas de la Alcaldía Mayor de Tegucigalpa consideraban que la Constitución abolía el tributo del derecho señorial que se les había impuesto desde 1523, mientras que las autoridades políticas opinaban lo contrario. Esta interpretación particular de la Constitución confrontó a los pueblos indígenas con los funcionarios imperiales locales, conduciendo a una crisis que estuvo al borde de desembocar en un alzamiento popular. Ya que la Constitución estaba entrando en vigencia en una sociedad pre-constitucional, no era del todo claro para los habitantes de las poblaciones españolas si este nuevo documento abolía todas las leyes anteriores o si era complementario e inclusivo de estas.

Partiendodeloanterior, en estainvestigación se adopta una postura comparativa entre los argumentos de los pueblos indígenas y las autoridades españolas, discutiéndose las razones expuestas por cada parte en el asunto. La dimensión temporal del estudio son los últimos cuatro meses del año de 1820 , periodo que comprende la negativa de los pueblos indígenas a pagar el tributo por la puesta en vigencia de la Constitución y la resolución del conflicto. Los datos han sido extraídos de fuentes primarias del Fondo Colonial del Archivo Nacional de Honduras, conservándose la ortografía original en los casos de citación directa.

\section{PROBLEMA DE INVESTIGACIÓN}

El cobro del derecho señorial fue una de las imposiciones tributarias de mayor duración durante el dominio castellano en Indias. Su imposición jurídica se remonta a una cédula del Rey Carlos I emitida el 15 de julio de 1523, posteriormente refrendada por Felipe II en 1573 y por Carlos II durante su reinado. El tributo fue incorporado a la Recopilación de Leyes de Indias de 1680 en la Ley I del Titulo 
V del Libro VI del segundo tomo, leyendo parte del texto de la ley de la siguiente manera:

Porque es cosa justa, y razonable, que los Indios, que se pacificaren, y reduxeren [sic] a nuestra obediencia y vassallage [sic], nos sirvan, $\mathrm{y}$ den tributo en reconocimiento del señorío, y servicio, que como nuestros súbditos y vassallos [sic] deben, pues ellos también entre sí tenían costumbre de tributar a sus Tecles, y Principales: Mandamos, que se les persuada a que por esta razón nos acudan con algún tributo en moderada cantidad de los frutos de la tierra, como, y en los tiempos, que se dispone, por las leyes de este titulo. (Recopilación de Leyes de Indias, 1756, p.208).

El derecho señorial era, entonces, una institución feudal, que garantizaba al Rey un influjo de bienes de parte de sus vasallos y, a estos, la protección del monarca y el derecho de vivir y laborar en sus tierras. La justificación del cobro era eminentemente ius naturalista (Pérez, 1992), procediendo de la condición del indio como vasallo del Rey, estado que había adquirido al momento de la conquista. Durante todo el periodo colonial, la institución del tributo se mantuvo firme, enfrentando solamente ciertas reformas durante la mitad del siglo XVIII, que garantizaban su efectivo cobro, siguiendo la línea de centralización del aparato estatal aplicada por los monarcas borbones.

Las condiciones políticas para la abolición de este antiguo derecho se presentan a partir de 1808, año en que Napoleón invadió España y depuso al monarca Fernando VII, colocando en el trono a Felipe Bonaparte. Esto condujo al establecimiento de un Consejo de Regencia de parte de la nobleza que permanecía fiel a los monarcas borbones y, a la convocatoria a
Cortes, las cuales posteriormente redactaron la Constitución de la Monarquía Española en 1812. Según Aaron Pollack (2016, pp.109110) el Consejo de Regencia se vio influido por tres situaciones particulares para abolir el tributo del derecho señorial: primero, la necesidad de congraciarse con los sectores populares para evitar brotes independentistas o revolucionarios en América; segundo, el hecho de que la abolición del tributo significaría la disolución de varias corporaciones indígenas que podían ser apropiadas por el gobierno y; tercero, la posibilidad de la imposición de nuevos cobros a los indios, como la alcabala.

La abolición oficial del tributo indígena se realizó en dos etapas: en primera instancia se expidió una orden del 26 de mayo de 1810 , en el cual los indios de la Nueva España quedaban exentos del pago y; en segundo punto, esta gracia fue extendido a todos los indios de las posesiones españoles en América mediante el Decreto XLII del 13 de marzo de 1811 (Cortes Generales, 1820, pp.79-80). Si bien este decreto representa la abolición del tributo del derecho señorial, el logro sería de corta duración, ya que una vez reinstaurado en el trono Fernando VII, aprobaría en 1815 un nuevo tributo que mimetizaba el antiguo derecho feudal establecido por Carlos I (Earle, 2015, p.127). El restablecimiento de esta medida y también del absolutismo llevó a una serie de revueltas que concluyeron con la reimposición de la Constitución Política de la Monarquía Española en 1820.

Los pueblos indígenas comprendieron el retorno de la Constitución como la abolición definitiva de los tributos, sin embargo, en ningún artículo de esta Carta Magna se hace 
mención a la abolición tributaria. En materia de interpretación constitucional, el artículo en disputa era el 338 del Título VII el cual afirmaba que los tributos serían confirmados anualmente por las Cortes (Constitución Política de la Monarquía española, 1812, p.93). Ernest Sánchez (2011) considera el Artículo 339 del Título VII como el más revolucionario en cuanto a materia tributaria, ya que este ordenaba que los tributos al reino fuesen distribuidos entre todos los españoles del Imperio, eliminando así las distinciones antiguas de castas y clases sociales que habían dividido a los sujetos del Rey por siglos.

En el caso de la Alcaldía Mayor de Tegucigalpa -y cómo se expondrá en esta investigación-, la materia tributaria del derecho señorial de la Constitución Política de la Monarquía Española generó una crisis por su interpretación. Varios pueblos indígenas alegaron -justificadamente- que la reimposición de la Constitución significaba la abolición definitiva de los tributos, mientras que las autoridades locales adoptaron una postura ambivalente, ora alegando que no contaban con la potestad para pronunciarse sobre la materia, ora ordenando el pago inmediato del derecho. Puede considerarse esta situación como una de las primeras crisis constitucionales sufridas en los territorios que actualmente componen la República de Honduras.

\section{METODOLOGÍA}

En la presente investigación se adopta una metodología comparativa, utilizándose, en específico, la técnica del análisis comparativo configurativo, la cual es orientada al estudio de casos. Según Benoit Rihoux y Charles Ragin (2009), el análisis comparativo configurativo considera los casos particulares como una combinación de fenómenos complejos que se aúnan en situaciones específicas para brindar objetos de estudios a partir de los cuales es posible formular generalizaciones. Por esta razón los casos deben de ser relevantes en su contexto histórico y seleccionados con la intencionalidad de cubrir el mayor espectro de posibilidades posibles. Este método de análisis es complementado con una reconstrucción del momento histórico de la época, la cual se ha apegado a la metodología de la historia que Surbhi Jain (2019) define como el estudio del contexto histórico que rodea el fenómeno estudiado.

Los datos de la investigación han sido extraídos de documentos del Fondo Colonial del Archivo Nacional de Honduras, correspondiente al año de 1820. A partir de la metodología seleccionado, estos textos del Archivo Nacional de Honduras han sido utilizados para reconstruir una narrativa histórica que permita contextualizar el problema estudiado. Una vez se ha planteado el problema histórico, se ha comparado el texto de las fuentes primarias, para extraer de estas las interpretaciones particulares que actores de la época tenían sobre la abolición del cobro del derecho señorial en la Constitución Política de la Monarquía Española.

\section{RESULTADOS DE INVESTIGACIÓN}

En marzo de 1820, el Rey Fernando VII juró la Constitución de 1812, enviándose ordenes a las autoridades coloniales de promulgar esta Carta Magna en sus territorios y proceder, 
inmediatamente, a la elección de funcionarios apegados a la nueva normativa. En la Alcaldía Mayor de Tegucigalpa, la Constitución de la Monarquía arribó el 10 de julio (Soriano, 2012), celebrándose prontamente su imposición y los ritos requeridos para el caso. Los problemas generados por el nuevo régimen no se hicieron esperar, reportándose reclamos por los métodos de la elección de diputados desde el 22 de julio (Archivo Nacional de Honduras, 1820), solamente doce días después del inicio del nuevo periodo constitucional.

El murmullo popular generado por la instauración de la Constitución reverberó de tal manera que rumores de que los pueblos indígenas no pagarían sus tributos alcanzaron al Alcalde Mayor. Asumiendo su rol como autoridad política superior del territorio, el Alcalde Mayor Narciso Mallol decidió dirigir una cordillera a sus tenientes en los partidos de su jurisdicción con fecha de 1 de agosto, aclarándoles lo que se debía de hacer en caso de que los pueblos indígenas se negasen a pagar el derecho señorial. El texto es corto, explicándose esta brevedad porque el Alcalde Mayor no estaba interesado en adentrarse en debates hermenéuticos, sino, simplemente, cobrar el tributo:

Haviéndose [sic] entendido mal por algunos de los pueblos indios, q. [sic] con motibo [sic] de la Constitución política de la monarquía ya no deve [sic] pagarce [sic] el tributo, prevengo a V. [sic] haga entender a todos los contribuyentes del distrito de su cargo q. [sic] siguen con los pagos de tributos, comunidad y sueldo, sin hacerce [sic] novedad y que desde luego concurran a pagar el tercio vencido. (Archivo Nacional de Honduras, 1820 b, p.1).
Lo primero que se debe notar es que el Alcalde Mayor afirmaba que cualquier interpretación indígena de la abolición del tributo era errónea, esto quizá porque en la misma Constitución no se hacía referencia a tal acción. Sin embargo, debe de apuntarse, que los artículos 338 y 339 del Título VII, establecían que los tributos que deberían de ser pagados por los ciudadanos españoles se fijarían anualmente y su monto sería decidido por las Cortes. Parte del problema se debía a que la Constitución Política fue redactada con una visión universalista del nacionalismo hispánico, por lo que sus promulgadores expidieron un nuevo contrato social que no aclaraba el destino de las situaciones particulares de las múltiples provincias del Imperio.

Un segundo punto a observar en la cordillera del Alcalde Mayor es que este afirmaba que no había ninguna novedad en cuanto al cobro de los tributos. Esto puede interpretarse como un esfuerzo por el funcionario en ignorar los problemas postulados por la nueva constitución, prefiriendo conservar las antiguas instituciones hasta que se celebrasen elecciones. Esta renuencia del Alcalde Mayor por abordar el texto mismo de la Constitución condujo a que varios pueblos de indios se negaran al pago, arguyendo que su propia interpretación de la Carta Magna así lo preveía.

El 20 de agosto se registró el primer indicio de conflictos con los pueblos indígenas. En esa fecha, el funcionario Juan Bautista Ordoñez comunicó al Alcalde Mayor que los indios del pueblo de Texiguat habían iniciado a oponerse al pago del tributo (Archivo Nacional de 
Honduras, 1820c). Lo más alarmante de esta nota era que el funcionario español afirmaba que la oposición al pago era hecha a pesar de que los indios estaban enterados de la orden de seguir tributando. Dada la ausencia de documentos adicionales acerca del tema, es posible afirmar que los indios cedieron en sus pretensiones y el cobro de los tributos se realizó como era acostumbrado.

Las tensiones continuaron elevándose, hasta que el 8 de noviembre los alcaldes de Comayagüela dirigieron una cordillera convocando a sus pares de los pueblos de indios de Santa Ana, Ojojona, Curaren, Alubaren, Reytoca, Aguanqueterique y Lepaterique. Esta nota era una respuesta directa a aquella expedida por el Alcalde Mayor y, tenía como objetivo reunir a todos los pueblos de indios para exigirle al Capitán General la reducción de los tributos. En el texto queda claro que los alcaldes de Comayagüela consideraban el cobro del derecho señorial como una figura antigua que ya no se les aplicaba:

Muy señores Nuestros esta ntra. [sic] carta citatoria solo se dirige a noticiar a todos vmd.s [sic] sobre el particular en que nos hallamos nosotros por aquí con Ntro. [sic] Alc.e [sic] Mayor que nos dice que hemos de seguir pagando los Reales derechos y todo cuanto compendio Antiguo hemos tenido los pueblos y así noticiamos a Vmd.s [sic] que determinamos aser [sic] despacho Ante el señor Capitán General y a la Real Junta Provincial por que nos a dado una horden [sic] escrita para que cobremos con fuersas [sic] los Reales derechos. (Archivo Nacional de Honduras, 1820d, p.9).

Al igual que con la cordillera del Alcalde Mayor, la comunicación de los indios de Comayagüela no incluye mucha información interpretativa con respecto a la Constitución. De especial atención es que se refirieran al tributo del derecho señorial como "compendio antiguo", lo que revela que las autoridades de estos pueblos comprendían que la Constitución Política era el inicio de un nuevo orden social, en el cual todos los viejos derechos feudales habían quedado abolidos. Que las autoridades indígenas de Comayagüela hayan propuesto arreglar el asunto con el Capitán General -el funcionario superior del distrito- indica que estos no consideraban que una negociación con el Alcalde Mayor sería fructuosa.

Al parecer, la situación se agravó en las poblaciones indígenas de la Alcaldía Mayor. El 15 de noviembre, José María del Campo, informó al Alcalde Mayor que los indios de Curaren habían hecho una junta en la cual habían despojado de su vara de justicia a un alguacil, agregando que la cordillera de Comayagüela había sido recibida en Lepaterique y Lauterique (Archivo Nacional de Honduras, 1820d). Al día siguiente, este mismo funcionario se quejó ante el Alcalde Mayor de que, a partir de la jura de la Constitución se había perdido el orden en las poblaciones de indios:

Atendiendo a la cituacion [sic] en q.e [sic] se hallan estas reduciones [sic], p.r [sic] con la publicación de la Constitución se han llenado de tal miedo los jueses [sic] q.e [sic] todos los delitos se quedan impunes, y p.r [sic] conciguiente [sic] la altanería ba [sic] en aumento: los delitos q.e [sic] mas abundan son amancebam.t [sic], falta de obediencia a los jueses [sic], asuntos de devitos [sic], y otros a este tenor. (Archivo Nacional de Honduras, 1820d, pp.5-6). 
Ante la delicada situación, el Alcalde Mayor Narciso Mallol ordenó a sus tenientes de partido comunicarse con las autoridades de indios y preguntarles si habían recibido la convocatoria de Comayagüela y qué habían determinado a partir de esta. En Ojojona, Lepaterique y Santa Ana, las autoridades indígenas afirmaron que, a pesar de haber recibido la cordillera desde Comayagüela, habían decidido no pronunciarse en el asunto por considerarlo improcedente. La inacción de los pueblos indígenas y la intransigencia del Alcalde Mayor pusieron fin al conflicto, el cual concluyo en el cobro normal de los tributos.

Desde una perspectiva comparativa, la interpretación de la Constitución por el Alcalde Mayor y por los indios de Comayagüela fue diametralmente opuesta. Por una parte, las autoridades españolas pensaban que la promulgación del nuevo documento no sobreseía los antiguos derechos; mientras que los indios postulaban que este nuevo contrato social establecía normas que invalidaban todas las legislaciones pasadas. Estas interpretaciones confrontadas no se basaban en principios jurídicos o en un estudio ponderado del texto constitucional, sino que respondían a los intereses de las partes: el Alcalde Mayor buscaba mantener el orden de su provincia y cumplir con su obligación ante el Rey de entregarle el tributo; los indios querían librarse de la carga fiscal que se les había impuesto desde 1523.

Una comparación de las acciones de ambas partes cede, igualmente, la idea de que los dos bandos se encontraban en extremos opuestos en el asunto. Desde antes que los pueblos indígenas se pronunciaran, las autoridades españolas les hicieron saber que la promulgación de la Constitución no cambiaba su situación tributaria y que estos debían de continuar actuando como en el régimen antiguo. A su vez, los pueblos indígenas se pronunciaron en sus reuniones de cabildos y convocaron a una unión para oponerse a la continuada explotación fiscal. Ninguno de los bandos tomó acciones en contra del otro, fracasando la iniciativa de los pueblos de indios $\mathrm{y}$, triunfando la resistencia de los españoles.

A pesar de que no condujo a mayores males, la crisis generada por las interpretaciones confrontadas de la Constitución Política presagió la venidera independencia de Honduras de España, que se lograría tan solo un año después de su promulgación. A partir de la reconstrucción histórica expuesta en este artículo se puede afirmar que las tensiones sociales en la Alcaldía Mayor de Tegucigalpa habían alcanzado su ápice. Ciertamente, se percibe que los pueblos indígenas añoraban un cambio en su contrato social con la monarquía. Si bien es cierto que la promulgación de la Constitución de 1812 era un primer paso para este deseado cambio social, la renuencia de las autoridades españolas a aplicar las reformas y la vaguedad en que las leyes estaban redactadas, terminaron por convencer a la población que una separación con España era el mejor camino a tomar.

\section{CONCLUSIONES}

- La Constitución Política de la Monarquía Española introdujo una serie de innovaciones liberales a los territorios 
bajo el dominio de la corona castellana, siendo bien recibida al momento de su juramentación. No obstante, su carácter universalista, que englobaba a todas las culturas diversas que existían en el Imperio Español, causó una serie de disputas por la interpretación de sus leyes. En el caso de la Alcaldía Mayor de Tegucigalpa, uno de los principales conflictos generados por la nueva Carta Magna fue el asunto de la abolición del cobro del derecho señorial, institución feudal que no era compatible con la modernidad liberal de las nuevas leyes.

- Narciso Mallol, el Alcalde Mayor de Tegucigalpa, ofreció su interpretación personal sobre el asunto de los tributos indígenas a luz de la Constitución. Según este funcionario, el cobro debía de seguir realizándose pues la Constitución no abolía el derecho señorial del Rey. Para imponer su interpretación personal, el Alcalde Mayor hizo uso de sus tenientes de partido, a quienes les ordenó continuar la recaudación del tributo como era la costumbre. Esta acción exacerbó los ánimos de los pueblos indígenas quienes respondieron, en ocasiones, con una oposición al pago de sus derechos.

- Hay evidencia para afirmar que varios pueblos indígenas de la Alcaldía Mayor de Tegucigalpa se opusieron con vehemencia al pago de los tributos, basándose en su propia interpretación de la Constitución, la cual consideraban abolía el pacto social anterior y establecía un nuevo acuerdo con el Rey. Para defender su postura, los indios de Comayagüela emprendieron una iniciativa que consistía en convocar a sus pares y solicitarle al Capitán General que redujese la medida fiscal. Esta acción fue un fracaso, en parte porque los demás pueblos decidieron no responder a la iniciativa $y$, por otro lado, porque es de suponerse que el texto constitucional era desconocido por la mayoría de la población.

\section{BIBLIOGRAFÍA}

Agencia Española de Cooperación Internacional para el Desarrollo. (2012). Bicentenario de la Constitución de Cádiz en Honduras. Tegucigalpa: AECID

Archivo Nacional de Honduras. (1820). Documento 5593, Caja 149. Tegucigalpa: Fondo Colonial

Archivo Nacional de Honduras. (1820b). Documento 5610, Caja 150. Tegucigalpa: Fondo Colonial

Archivo Nacional de Honduras. (1820c). Documento 5664, Caja 150. Tegucigalpa: Fondo Colonial

Archivo Nacional de Honduras. (1820d). Documento 5920, Caja 155. Tegucigalpa: Fondo Colonial

Cassagne, J. (2012). El bicentenario de la constitución de Cádiz y su proyección en Iberoamérica. Anuario da Facultade de Dereito da Universidade da Coruña, (16), pp.335-356 
Constitución Política de la Monarquía Española. (1812). Constitución Política de la Monarquía Española. Cádiz: Cortes de Cádiz

Cortes Generales. (1820). Colección de los decretos y ordenes que han expedido las Cortes Generales y Extraordinarias desde su instalación. Sevilla: Imprenta Mayor de la Ciudad

Earle, R. (2015). España y la independencia de Colombia, 1810-1825. Bogotá: Universidad de los Andes

Garay, N. (2012). Igualdad y perspectiva de género: a propósito del bicentenario de la Constitución de 1812. Pensamiento Constitucional, (17), pp.199-224

Georges, L. (2012). Coloquio Internacional: «La Constitución de 1812 en su Bicentenario. Bulletin de l'Institut français d'études andines, 41(2), pp.299-303.

Jain, S. (2019). Research methodology in arts, science and humanities. Oakville: Society publishing

Pérez, A. (1992). Los iusnaturalistas clásicos hispanos y la polémica sobre el Nuevo Mundo. Revista de Estudios Políticos, (77), pp.7-31

Pollack, A. (2015). Hacia una historia social del tributo de indios y castas en Hispanoamérica. Notas en torno a su creación, desarrollo y abolición. Historia Mexicana, 66(1), pp.65-160
Recopilación de Leyes de Indias. (1756). Recopilación de leyes de los reynos de las indias: tomo II. Madrid: Antonio Balbas

Rihoux, B. y Ragin, C. (2009). Configurational comparative methods: comparative analysis (QCA) and related techniques. Californa: Sage publications

Sánchez, E. (2011). Guerra y restauración del antiguo régimen fiscal en Nueva España: la Junta Menor de Arbitrios de 1815. Jahrbuch für Geschichte Lateinamerikas, (48), pp.57-81

Saenz, J. (2015). Historia del Derecho hondureño: libro segundo. El Derecho nacional. San José: Ministerio de Relaciones Exteriores y Culto

Soriano, E. (2012). Una aproximación a las experiencias del juramento de la Constitución de Cádiz en el contexto de Tegucigalpa (1812-1820). En Agencia Española de Cooperación Internacional para el Desarrollo (Eds.), Bicentenario de la Constitución de Cádiz en Honduras. Tegucigalpa: AECID 